\title{
Intramolecular Free Radical Cyclizations Using Acylsilanes as Radicalphiles
}

\author{
Yeun-Min Tsai,* Chaur-Donp Cherng \\ Department of Chemıstry, Natınal Taıwan University, Taıpei 10764, Taiwan, Republıc of Chına \\ Key Words radical cyclization. acylsilane, radical Brook rearrangement, radical addition to carbonyl; cyclopentanol
}

\begin{abstract}
Carbon radicals add intramolecularly to acylsilanes at the carbonyl carbon followed by radical Brook rearrangement to give sllylated cyclopentanols or cyclohexanols in good yichs
\end{abstract}

The use of radical reactions in organic synthesis has been studied very intensively in recent years; ${ }^{1}$ however, the attentions are mostly centered on radical additions to carbon-carbon multple bonds. Although there are some recent novel applications about addition of carbon radicals to carbonyls, ${ }^{2}$ the research in this direction is quite scarce. Kunetic studies revealed that radical additions to carbonyls are reversible and the fragmentation rates are faster than the cyclization rates (Scheme 1). ${ }^{3}$ Thus it is not surprising that cyclizations of this type are most successful in some quite ngid systems ${ }^{2 a, 2 c}$ where Thorpe-Ingold effect ${ }^{4}$ operates. Others elegantly manipulated this reversible phenomenon in nng enlargement processes. $2 \mathrm{~d}-\mathrm{g}$

\section{Scheme 1}
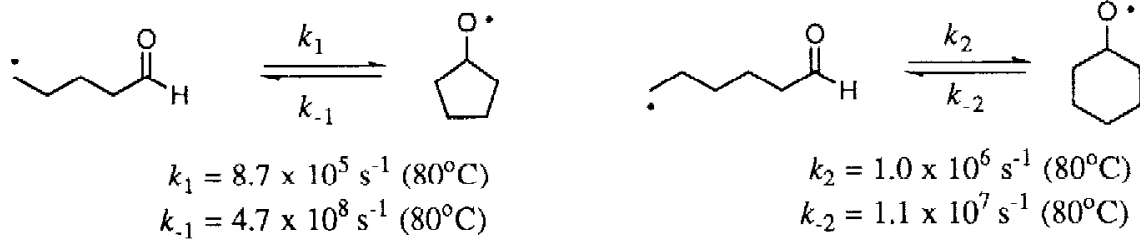

We are also interested in radical additions to carbonyls Conceptually, if one wishes to shift the equilibnum towards the cyclization side one should design etther a system in which the stability of the alkoxy radical is enhanced or trap the alkoxy radical urreversibly as soon as it is formed. Acylsilane ${ }^{5}$ appears to be excellent candidate along this line because silyl group is known to be able to stabilize radical $\alpha^{6 a-c, 7}$ or $\beta^{6}$ to it (Scheme 2). The possibility of an urreversible radical Brook rearrangement ${ }^{8}$ is also likely. In this communication we wish to report our initial success in this direction.

We first prepared bromide $\mathbf{2 a}(79 \%)$ by alkylaton of silyldthiane $1^{9}$ with 1,4-dibromobutane (Scheme 3). ${ }^{10}$ Hydrolysis ${ }^{11}$ of $2 \mathrm{a}$ gave the desired bromoacylsilane $3 \mathrm{a}$ in $86 \%$ yicld. ${ }^{12}$ Compounds such as $2 \mathrm{a}$ are not stable and we recommend to perform the hydrolysis step using the crude product as soon as it is obtained.

Slow addition $(6 \mathrm{~h})$ of a solution of tributyltin hydnde $(13$ equiv, $0.13 \mathrm{M})$ and catalytic amount of 
Scheme 2

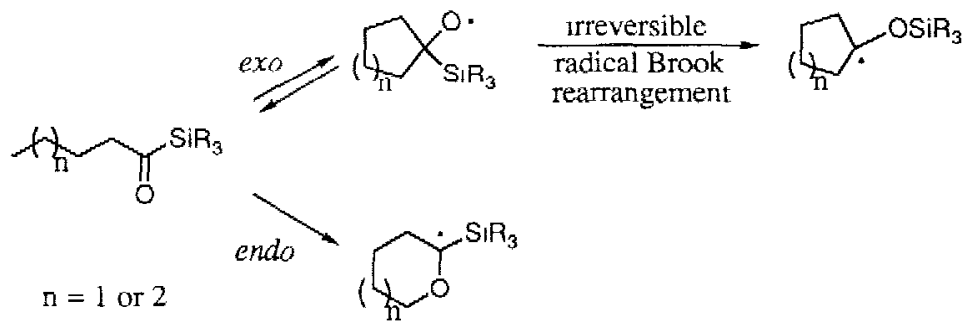

azobisisobutyronttrle (AIBN) in benzene to a solution of $3 \mathrm{a}$ in benzene $(0.1 \mathrm{M})$ heated at $80^{\circ} \mathrm{C}$ gave cyclopentyl trimethylsilyl ether (4a) as the only product by $\mathrm{GC}$ analysis and no stratght reduction product was detected. However, since 4 a was too volatule to be completely removed from benzene we directly treated the cyclization muxture with a tetrahydrofuran solution of tetrabutylammonium fluonde, bcnzoyl chloride and trethylamine to give the benzoate $13 \mathbf{a}$ in $68 \%$ solaton yield. Similarly, bromoacylsilane $\mathbf{3 b}$ ( $64 \%$ from $\mathbf{1}$ ) also gave benzoate 13b (62\%) under the same reaction conditions. Thus, it is most likely that the radical cyclization process occurred in an exo mode followed by a Brook rearrangement as expected (Scheme 2). We were not able to detect any product denved from endo mode of cyclizanon

It is well-known that in radical cyclization reactions steric hindrance at the site of attack decreases the cyclization rate la Therefore, it is interesting to examne the effect of the stenc bulkiness of the slyl group on the acylslane cyclization reactions Bromoacylslane 7a (54\%) was synthesized from 5 accordingly. Under the same cyclization condition we were able to isolate the less volatile silyl ether 8 a in $80 \%$ yield. Agan no other types of product were found. Even in the case of the cyclization of 11a (73\% from 9), silyl ether 12a was the only product isolated ( $81 \%$ ) Apparently the steric effect of the silyl group is minimal at least for the slyl groups that we choose.

Since chloroacylsilane such as $\mathbf{1 4}$ can be prepared in higher yeld via alkylation of 9 with 1 -bromo-4chlorobutane ( $92 \%$ ) followed by hydrolysis $(91 \%)$, we decided to see if this kind of chloro compound could be useful. As shown in equation (1), under the same reaction conditions mentioned above we were able to isolate in $47 \%$ yield of the expected cyclization product $12 \mathrm{a}$ in addition to $3 \%$ of straight reduction product $15,13 \%$ of $16,30 \%$ of 17 , and $6 \%$ of 18 . $\alpha$-Silyl alcohol 16 is probably derived from tin hydride reduction of the

Scheme 3

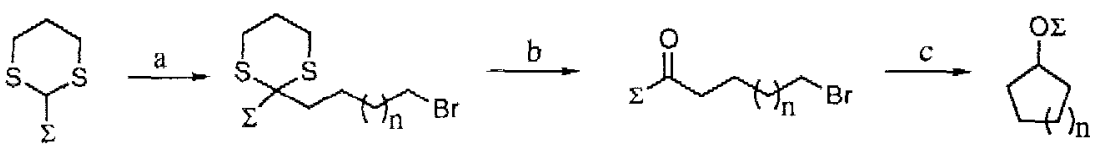

a $\mathrm{n}=1 \quad \mathbf{b} \mathrm{n}=2$
$1 \Sigma=\mathrm{Me}_{3} \mathrm{~S}_{1}$
$2 \Sigma=\mathrm{Me}_{3} \mathrm{~S}_{1}$
$3 \quad \Sigma=\mathrm{Me}_{3} \mathrm{~S}_{1}$
$5 \Sigma={ }^{t} \mathrm{BuMe}_{2} \mathrm{Si}$
$6 \quad \Sigma={ }^{t} \mathrm{BuMe}_{2} \mathrm{~S}_{1}$
$7 \Sigma={ }^{\mathrm{BuMe}_{2} \mathrm{Si}}$
$9 \Sigma=\mathrm{Ph}_{2} \mathrm{MeS} 1$
$10 \Sigma=\mathrm{Ph}_{2} \mathrm{MeSi}$
$11 \Sigma=\mathrm{Ph}_{2} \mathrm{MeSi}$

$$
\text { d }\left[\begin{array}{cl}
4 & \Sigma=\mathrm{Me}_{3} \mathrm{Si} \\
8 & \Sigma=t_{\mathrm{BuMe}} \mathrm{Si} \\
12 & \Sigma=\mathrm{Ph}_{2} \mathrm{MeSi} \\
13 & \Sigma=\mathrm{COPh}
\end{array}\right.
$$

(a) BuLl (1 equiv), THF; $\mathrm{BrCH}_{2} \mathrm{CH}_{2}\left(\mathrm{CH}_{2}\right)_{n} \mathrm{CH}_{2} \mathrm{Br}$ (2 equiv) (b) $\mathrm{HgO}$ (2 equiv), $\mathrm{BF}_{3} \cdot \mathrm{OEt}$ (2 equiv), Celite, THF, $\mathrm{H}_{2} \mathrm{O}$ (c) $\mathrm{Bu} 3 \mathrm{SnH}$ (1.3 equiv), AIBN (5 mol\%), $\mathrm{PhH}, 80^{\circ} \mathrm{C}$ (d) $\mathrm{Bu} 4 \mathrm{NF}$ (2.5 equiv)/THF, PhCOCl (5 equiv), Et ${ }_{3} \mathrm{~N}$ ( 4 equiv), $80^{\circ} \mathrm{C}$ 
Table 1. Concentration study of the cyclization of acylsilane 11a. ${ }^{\mathrm{a}}$

\begin{tabular}{cccc}
\hline Entry & Concentration $(\mathrm{M})^{\mathrm{b}}$ & Time $\left.^{\mathrm{h}} \mathrm{h}\right)^{\mathrm{c}}$ & Ratio (cyclization/reduction) $^{\mathrm{d}}$ \\
\hline 1 & 0.05 & 6 & $100 / 0$ \\
2 & 0.2 & 2 & $100 / 0$ \\
$3^{\mathrm{e}}$ & 0.5 & 1 & $100 / 0$ \\
$4^{\mathrm{f}}$ & 0.2 & 0.5 & $90 / 10$ \\
\hline
\end{tabular}

aThe reaction was performed by slow addition of a solution of tributyltin hydride (1.3 equiv) and AIBN $(5 \mathrm{~mol} \%)$ in benzene to a solution of $11 \mathrm{a}$ in benzene heated at $80^{\circ} \mathrm{C}$ under nitrogen. bThe concentration is the final concentration based on 11a. The initial concentration of $11 \mathrm{a}$ is double of this number. ${ }^{c}$ The time is the addition time of tributyltin hydnde solution. ${ }^{\mathrm{d}}$ The ratios were determined by ${ }^{1} \mathrm{H}$ NMR integration of the crude product ${ }^{\mathrm{e}} \mathrm{An} 80 \%$ isolation yield of the cyclization product 12a was obtained. PPerformed by direct mixing of 11a, tributyltin hydnde (1.3 equiv) and $\mathrm{AIBN}(5 \mathrm{~mol} \%)$ in benzene and heated under nitrogen at $80^{\circ} \mathrm{C}$ for $0.5 \mathrm{~h}$.

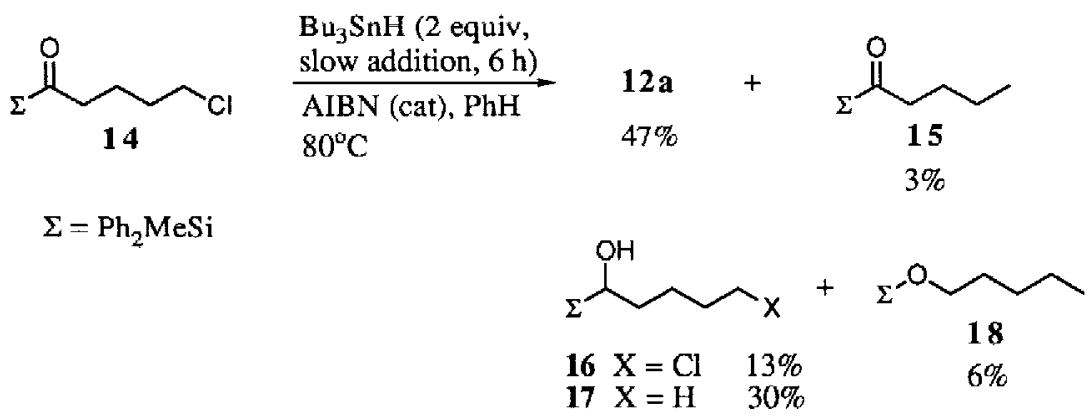

carbonyl. 13 Further reduction of 16 gives 17 . The exact origin of silyl ether 18 is not certain at this point and requires more detailed investigations. ${ }^{14}$ Thus it is revealed in this experiment that the rate of reduction of the acylsilane moicty by tributyltin hydride was comparable with that of the chlorides. This certainly imposes some limitations for this kind of cyclizations.

In order to see how efficient this type of cyclization is, we conducted a concentration study. As shown in Table 1, even direct heating of 11a and tributyltin hydride in benzene gave mostly the cyclization product (entry 4). In fact the cyclization reaction can be performed very practically by slow addition of tributyltin hydride over a relatively short period of time with a rather concentrated solution (entry 3 ).

In summary, the previously unnoticed radical chemistry of acylsilanes ${ }^{5}$ has been examined. Our experiments indicate that acylsilanes are excellent radical acceptors. This methodology constitutes a novel entry for the synthesis of molecules with cyclopentanol or cyclohexanol skeleton under neutral condition.

Acknowledgements. Financial support by the National Science Council of the Republic of China is gratefully acknowledged.

\section{References and Notes}

1. For recent reviews, see: (a) Giese, B. Radicals in Organtc Synthesis: Formation of Carbon Carbon Bonds; Pergamon Press: Oxford, 1986. (b) Curran, D. P. Synthesis 1988, 417, 489, and references 
cited therein. (c) Pattenden, G. Chem. Soc. Rev. 1988, 17, 361. (d) Giese, B. Angew. Chem. Int. Ed. Engl. 1989, 28, 969. (e) Laurd, E. R.; Jorgensen, W. L. J. Org. Chem. 1990, 55, 9. (f) Thebtaranonth, C.; Thebtaranonth, Y. Tetrahedron 1990, 46, 1385.

2. (a) Tsang, R.; Fraser-Reid, B. J. Am Chem Soc 1986, 108, 21 16, 8102. (b) Tsang, R,; Dickson, J. K.; Pak, H.; Walton, R.; Fraser-Reid, B. ibid, 1987, 109, 3484. (c) Dickson, J. K.; Tsang, R.; Llera, J. M.; Fraser-Re1d, B. J. Org. Chem. 1989, 54, 5350. (d) Beckwith, A. L. J.; O'Shea, D. M.; Gerba, S.; Westwood, S. W, J. Chem. Soc. Chem. Commun. 1987, 666. (e) Dowd, P.; Choi, S -C. J. Am. Chem. Soc 1987, 109, 3493, 6548. (f) Baldwin, J. G., Adlıngton, R. M.; Robertson, J. J. Chem. Soc Chem. Commun. 1988, 1404. (g) Boger, D. L.; Mathvink, R. J. J. Org. Chem 1990, 55, 5442.

3. (a) Beckwith, A. L. J.; Hay, B. P. J. Am. Chem. Soc 1989, 111, 230, 2674. (b) Giese, B.; Heinrich, N.; Horler, H.; Koch, W.; Schwarz, H. Chem. Ber 1986, 119 , 3528. (c) Wollowitz, S.; Halpern, J. J. Am. Chem. Soc. 1988, 110, 3112.

4. Beckwith, A. L. J.; Lawrence, T. J. Chem. Soc. Perkin Trans. II 1979, 1535.

5 For recent reviews of acylsilanes, see; (a) Ricci, A., Degl'Innocenti, A. Synthesis 1989, 647. (b) Page, P. C. B.; Klair, S. S.; Rosenthal, S. Chem. Soc. Rev. 1990, 19, 147.

6 (a) Jackson, R. A.; Ingold, K. U.; Griller, D.; Nazaran, A. S. J. Am. Chem. Soc. 1985, 107, 208. (b) Davidson, I. M. T.; Barton, T.; Hughes, K. J.; Ijadi-Maghsoodi, S.; Revis, A.; Paul, G. C. Organometallics 1987, 6, 644. (c) Wilt, J. W.; Lusztyk, J.; Peeran, M.; Ingold, K. U. J Am Chem Soc. 1988, 110, 281. (d) Lyons, A. R.; Symons, M. C. R. J. Chem. Soc. Faraday Trans. II, 1972, 68, 622. (e) Griller, D ; Ingold, K. U. J. Am. Chem. Soc. 1974, 96, 6715. (f) Auner, N.; Walsh, R.; Westrup, J. J. Chem. Soc. Chem. Commun 1986, 207. (g) Block, E.; Yencha, A. J.; Aslam, M.; Eswarakrishnan, V.; Luo, J.; Sano, A. J. Am. Chem. Soc. 1988, 110, 4748. (h) Swenton, J. S.; Platz, M.; Venham, L. D. J. Org. Chem. 1988, 53, 2764. (i) Miura, K.; Oshima, K.; Utimoto, K. Tetrahedron Lett. 1989, 30, 4413.

7. (a) Wilt, J W.; Kolewe, O.; Kraemer, J. F. J Am. Chem Soc 1969, 91, 2624. (b) Pitt, C. G. J. Organomet. Chem. 1973, 61, 49. (c) Doncaster, A. M.; Walsh, R. J. Chem. Soc. Faraday Trans. I, 1976, 72 (d) Wilt, J. W,; Belmonte, F. G.; Z1eske, P. A. J Am Chem. Soc. 1983, 105, 5665. (e) Furth, P. S.; Hwu, J. R. ibid, 1989, 111, 8834, 8842. (f) Hwu, J. R.; Glbert, B. A.; Lin, L. C.; Liaw, B. R. J. Chem. Soc. Chem. Commun 1990, 161.

8. For 1onic Brook rearrangement, see: Brook, A. G. Acc. Chem. Res. 1974, 7, 77. For the radical version, see: Dalton, J. C.; Bourque, R. A J. Am Chem Soc. 1981, 103, 699.

9. (a) Brook, A. G.; Duff, J. M.; Jones, P. F.; Dav1s, N. R. ibid, 1967, 89, 431. (b) Corey, E. J.; Seebach, D.; Freedman, R. $t$ bid, 1967, 89, 434.

10. All new compounds mentioned give satisfactory ${ }^{1} \mathrm{H}$ NMR, ${ }^{13} \mathrm{C}$ NMR, IR and elementary analysis.

11. Vedejs, E.; Fuchs, P. L. J. Org. Chem. 1971, 36, 366.

12. Controlled experiment indicated that $3 \mathbf{a}$ was stable by heating in benzene under reflux overnight.

13. Although to our knowledge the reduction of acylsilane with tributyltin hydride has not been reported, the reduction of carbonyl with tin hydride is well-known, see: Pereyre, Y.; Quintard, J.-P.; Rahm, A. Tin in Organic Synthesis; Butterworth: Boston, 1987; Chapter 4, pp. 69-80. For more recent example, see: Enholm, E. J.; Prasad, G. Tetrahedron Lett. 1989, 30, 4939.

14. Simply heatıng $\mathbf{1 7}$ in benzene at reflux temperature overnight did not give 18. 